\title{
Efficacy of felodipine in chronic congestive heart failure: a placebo controlled haemodynamic study at rest and during exercise and orthostatic stress
}

\author{
ELI KASSIS, OLE AMTORP, STIG WALDORFF, PER FRITZ-HANSEN \\ From the Department of Cardiology, Gentofte Hospital, University of Copenhagen, Denmark
}

SUMMARY A vascular selective calcium antagonist, felodipine, was evaluated in a randomised, double blind, crossover trial in 18 patients with chronic congestive heart failure of ischaemic cause. Felodipine ( $10 \mathrm{mg}$ twice daily) or a corresponding placebo was added to conventional treatment. After three weeks haemodynamic function was assessed at rest, during a standard supine leg exercise, and during $45^{\circ}$ passive upright tilt. In patients in the supine resting position, felodipine reduced the mean arterial pressure $(9 \%)$ and systemic vascular resistance $(24 \%)$ and increased the stroke volume $\left(25^{\%}\right)$ and cardiac index $(23 \%)$. The heart rate and right and left ventricular filling pressures were unchanged. During felodipine treatment the standard exercise was accomplished at a similar cardiac index but at a substantially lower heart rate $(7 \%)$, arterial pressure $\left(10^{\circ}\right)$, systemic vascular resistance $(17 \%)$, and left ventricular filling pressure $(19 \%)$, and a higher stroke volume $\left(13^{\circ}{ }_{0}\right)$. During both placebo and felodipine administration there were substantial reductions in cardiac filling pressure during upright tilting. Upright tilting during the placebo phase did not increase the heart rate. It also caused a greater fall in systemic vascular resistance while the arterial pulse pressure but not the mean pressure was maintained and the cardiac index and stroke volume increased. The reduced cardiac filling pressures during the felodipine upright tilt were accompanied by reductions in arterial pulse pressure and stroke volume and the patients were able to maintain the mean arterial pressure by an increase in both the heart rate and systemic vascular resistance.

Thus three weeks treatment with felodipine improved haemodynamic function at rest and during standard exercise and normalised the baroreflex mediated haemodynamic response in patients with congestive heart failure. The haemodynamic efficacy of the drug in such patients may be associated with a baroreceptor mediated effect as well as with direct vasodilatation.

Various vasodilators have been increasingly used in the management of patients with congestive heart failure. This is because such treatment has a theoretical appeal and there are reports of its short term haemodynamic efficacy. ${ }^{1-4}$ Haemodynamic responses to initial doses of vasodilating drugs have been used as a guide for the selection and dose titration of vasodilators before embarking on long term treatment for congestive heart failure. ${ }^{34}$ These

Requests for reprints to Dr Eli Kassis, Medical Department B, Cardiology Laboratory, Rigshospitalet, Blegdamsvej 9, DK-2100 $\emptyset$ Copenhagen, Denmark.

Accepted for publication 1 June 1987 short term responses have recently been reported to have no relation to the long term effects of treatment. ${ }^{56}$ Some workers have reported long term haemodynamic benefits, however, ${ }^{7-11}$ but these have been questioned in other ${ }^{511} 12$ follow up studies of vasodilator treatment in congestive heart failure. This controversy cannot be exclusively attributed to the fact that patients can develop a tolerance to several vasodilators. ${ }^{13-15}$ Previous studies have mostly been uncontrolled and of small numbers of patients with congestive heart failure of variable severity and cause. Few adequately controlled trials have been reported. ${ }^{16-18}$ of the various vasodilators, angiotensin-converting-enzyme inhibitors 
have shown long term clinical efficacy in controlled studies of captopril ${ }^{1617}$ and enalapril. ${ }^{18}$

The systemic vasodilator and negative inotropic properties of currently available calcium antagonists ${ }^{19}$ account for their limited use as afterload reducing agents in congestive heart failure. Experimental studies have shown that felodipine, a new calcium antagonist, is a potent vasodilator with negligible effects on myocardial contractility. ${ }^{20}$ Promising haemodynamic effects have recently been reported in uncontrolled studies of felodipine in patients with congestive heart failure. ${ }^{21} 22$

We have evaluated the therapeutic response to felodipine in patients with congestive heart failure of ischaemic cause. The study was designed as a randomised, double blind, cross over comparison between felodipine and placebo in 18 ambulatory patients with congestive heart failure that was inadequately controlled by conventional treatment. We attempted to answer the questions: does adjunctive felodipine treatment in these patients have sustained haemodynamic benefits and what mechanisms other than the direct vasodilating effect are responsible for any beneficial effects of felodipine?

\section{Patients and methods}

\section{PATIENT SELECTION}

We studied 15 men and three women aged from 41 to 68 (mean 53.6) years. They all had severe congestive heart failure (New York Heart Association functional class III) despite treatment with digoxin and diuretics. Patients were required to have a past history of a myocardial infarction and echocardiographic evidence for myocardial dyssynergy. At least three weeks before the study all vasodilators, calcium antagonists, or $\beta$ blocking agents were discontinued while treatment with digoxin and diuretics was regulated and maintained. No patient was studied within three months of a myocardial infarction. Patients whose exercise ability was limited by angina pectoris or any cause other than fatigue or dyspnoea were excluded, as were those with systolic blood pressure below $100 \mathrm{~mm} \mathrm{Hg}$. Patients whose angiographic ejection fraction was $>30 \%$ were also excluded. All subjects were ambulant outpatients at the time of the study. The study protocol was approved by the ethics committee in Copenhagen and informed consent was obtained from each patient.

\section{STUDY DESIGN}

Preliminary clinical assessment was carried out two weeks before randomisation and digoxin and diuretic regimens were optimally set. Medications were continued unchanged and patients entered the study if they were clinically stable and had normal blood counts, electrolytes, and therapeutic serum concentrations of digoxin at the time of baseline assessment two weeks later. Patients were then randomly assigned to treatment with felodipine $5 \mathrm{mg}$ twice daily or to matching placebo tablets in a double blind fashion for two days. At this time, patients were clinically reviewed. If the systolic blood pressure was above $90 \mathrm{~mm} \mathrm{Hg}$ and no troublesome side effects were reported the drug dosage was doubled for a three week period. At three weeks, patients were clinically assessed and underwent right-sided heart catheterisation.

Control haemodynamic measurements were obtained at rest and during supine bicycle leg exercise for $5 \mathrm{~min}(50 \mathrm{~W})$ so that the patients became familiar with the test. The oral $10 \mathrm{mg}$ dose of trial drug was then given and patients rested for one hour. Blood samples were withdrawn to determine the plasma concentration of felodipine. Haemodynamic measurements at rest and exercise were repeated within 60 to $90 \mathrm{~min}$ after trial drug administration. Supine haemodynamic measurements were repeated after an hour's rest on a tilt table. Patients were then passively and slowly tilted to a $45^{\circ}$ angle and haemodynamic variables were measured within 5-10 min of the start of the tilt.

Patients crossed over to the second three week treatment period the day after heart catheterisation. At the end of the second treatment period we repeated the clinical assessment, noted the trial drug dosage increment after two days, and measured rest and exercise and supine and upright tilt haemodynamic variables.

\section{ASSESSMENT}

Clinical assessment was performed the day before heart catheterisation and included measurements of heart rate, blood pressure, body weight, ankle circumference (10 cm above the medial malleolus), and relative heart volume from a chest $x$ ray. An electrocardiogram was taken. Blood counts and electrolytes were analysed. The patients were asked to say whether they felt better, the same, or worse while on trial medication.

Right heart catheterisation at the end of each three week treatment period was undertaken during the same hours of the morning in each patient. A balloon tipped, triple lumen, thermodilution catheter (Gould SP 1435) was placed in the pulmonary artery under fluoroscopic control to measure cardiac output and pressures. Intracardiac pressures were recorded with Statham $\mathrm{P}_{23} \mathrm{Db}$ transducers. Patients rested supine for one hour before exercise and before upright tilt. Measurements at rest were repeated until five consecutive estimates with less 
than $10 \%$ variation were obtained for cardiac output and mean pulmonary capillary wedge pressure. Arterial blood pressure was measured by mercury column sphygmomanometer.

During the standard supine exercise, the electrocardiogram and right atrial and pulmonary artery pressures were monitored continuously; pulmonary capillary wedge and arterial pressures were recorded every minute. The pulmonary capillary wedge pressure at end expiration was used as a measure of left ventricular filling pressure except in five patients in whom the pulmonary artery diastolic pressure replaced an unsatisfactory wedge pressure tracing. Thermodilution cardiac output was measured in triplicate in the final two minutes of exercise and immediately before exercise was stopped.

Haemodynamic variables during upright tilt were measured within 5-10 min of the start of tilting and five consecutive estimates were obtained. The pressures were measured with reference to the midaxillary level in the supine position and to the right atrial level individually set for each patient in the upright tilted position.

Systemic vascular resistance $\left(\right.$ dyn $\mathrm{cm}^{-5}$ ) was calculated as $80 \times$ (mean arterial pressure minus right atrial pressure)/(cardiac output). Mean arterial pressure was calculated as diastolic blood pressure plus $1 / 3$ pulse pressure.

\section{STATISTICAL ANALYSIS}

When Student's $t$ test was used to analyse group differences, the confidence intervals were similar for the means and variances of the three week values for the variables measured at the two treatment periods. The results are given as mean (SEM). Student's paired $t$ test was used. A 0.05 level of significance was set.

\section{Results}

\section{CLINICAL FEATURES}

The 18 patients had experienced 29 previous episodes of acute myocardial infarction, with the last episode occurring five months before investigation. They all had classic symptoms of paroxysmal nocturnal dyspnoea or exertional dyspnoea and fatigue for at least five (mean 14.5) months before the study. Their mean (SE) daily doses of digoxin and frusemide were $0 \cdot 25(0.01)$ and $158(24) \mathrm{mg}$ respectively. Both dosages were kept constant. The patients had normal blood counts and electrolytes, were in sinus rhythm, and were not admitted to hospital during the two study periods.

Ten patients started on felodipine and eight on placebo. Felodipine $10 \mathrm{mg}$ twice daily. was well tolerated; drug related side effects were reported by two patients who experienced a burning sensation, which in one case was associated with pruritus. Felodipine was not detected in plasma samples taken during placebo treatment or in one patient during the felodipine period. This patient was retrospectively excluded. Concentrations of felodipine in the plasma during the 17 active treatment periods were $6 \cdot 6(1 \cdot 1)$ and $18 \cdot 8(3.5) \mathrm{nmol} / 1$ before and 1.5 hours after drug administration respectively.

During felodipine treatment seven $(41 \%)$ patients reported subjective improvement, five patients $(29 \%)$ reported no change, and five patients felt worse. During placebo treatment eight $(47 \%)$ patients felt better, five $(29 \%)$ patients reported no change, and the other four $(24 \%)$ patients felt worse. Thus the patients' subjective evaluation of wellbeing was similar during the placebo and felodipine periods.

Body weight was $78(2.3) \mathrm{kg}$ during felodipine treatment and $77 \cdot 7(2 \cdot 4) \mathrm{kg}$ during placebo $(\mathrm{p}=$ $0.91)$. There was a small and statistically significant increase in ankle circumference from $22 \cdot 3(0 \cdot 3) \mathrm{cm}$ during the placebo period to $22.9(0.4) \mathrm{cm}$ during the felodipine period $(\mathrm{p}<0.01)$. The relative heart volume was $731(38)$ and $739(32) \mathrm{ml} / \mathrm{m}^{2}(\mathrm{p}=0.88)$ during felodipine and placebo treatment respectively.

\section{HAEMODYNAMIC FEATURES}

Haemodynamic variables during rest and standard exercise

We excluded four sets of haemodynamic measurements at rest and five during standard exercise. During four treatment periods the measurements could not be made within 1.5 hours of administration of the trial drug and two patients underwent a 25 rather than $50 \mathrm{~W}$ standard exercise test.

Figures 1 to 3 compare individual data obtained during the placebo period with those obtained during the felodipine period. At rest felodipine did not affect the heart rate or the right atrial or pulmonary capillary wedge pressures but it did reduce the mean arterial pressure $(9 \%)$ and systemic vascular resistance $(24 \%)$ and it increased the stroke volume by $25 \%$. The cardiac index increased by $23 \%$ $(\mathrm{p}<0.01)\left(2.4(0.2)\right.$ and $3.0(0.2) 1 / \mathrm{min} / \mathrm{m}^{2}$ during the placebo and felodipine periods respectively).

During standard exercise felodipine reduced the heart rate $(7 \%)$, mean arterial pressure $(10 \%)$, systemic vascular resistance $(17 \%)$, and pulmonary capillary wedge pressure $(19 \%)$ and it increased the stroke volume by $13 \%$. The cardiac index during exercise was $3.7(0.3)$ and $3.9(0.3) 1 / \mathrm{min} / \mathrm{m}^{2}(\mathrm{p}=$ $0.53)$ during the placebo and felodipine periods respectively.

Figure 4 shows that left ventricular function was 

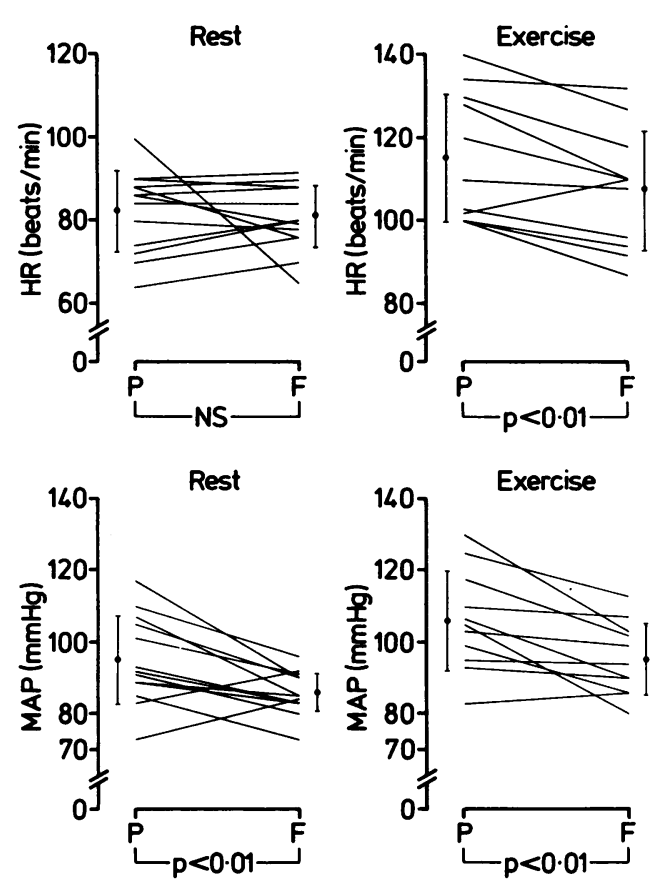

Fig 1 Effects of felodipine ( $F$ ) on heart rate (HR) and mean arterial pressure (MAP) compared with those of placebo $(P)$ in each patient at rest and during standard exercise. Points and bars are mean (SD).

improved by felodipine at rest and exercise: this was achieved with minimal changes in left ventricular filling pressure at rest, but there were significant reductions in this pressure during exercise.

\section{Haemodynamic variables during supine and upright} tilting

The table shows a complete set of measurements in ten patients. During upright tilt both the right and left ventricular filling pressures decreased substantially and to an equal extent during both the placebo and the felodipine periods. When patients were on placebo heart rate failed to increase, the systemic vascular resistance and mean arterial pressure fell, the arterial pulse pressure was maintained, and stroke volume and cardiac index increased in the upright tilted position. When the patients were on felodipine, the heart rate and systemic vascular resistance increased, mean arterial pressure was maintained, and the arterial pulse pressure and stroke volume index fell, while the cardiac index was maintained in the upright tilted position.

\section{Discussion}

The results of this randomised double blind trial indicate that additional treatment with an afterload reducing agent, felodipine $10 \mathrm{mg}$ twice daily, for three weeks produced a sustained haemodynamic improvement in patients with congestive heart failure. The present study shows that the clinical application of vasoselective calcium antagonists may usefully be extended to include the management of congestive heart failure.

The patients we studied had chronic manifestations of ischaemic heart disease with severe left ventricular dysfunction despite conventional treatment. The duration of symptoms and the haemodynamic estimates of congestive heart failure varied in these patients. The crossover design permits the comparison of physiological variables during the two treatment courses in the same patient. Treatment during the trial was generally well tolerated and patient compliance was established by measuring plasma felodipine concentrations. The rationale for measuring acute haemodynamic effects at the start of vasodilator treatment for congestive heart failure has recently been questioned. ${ }^{6}$ We avoided invasive measurements of haemodynamic
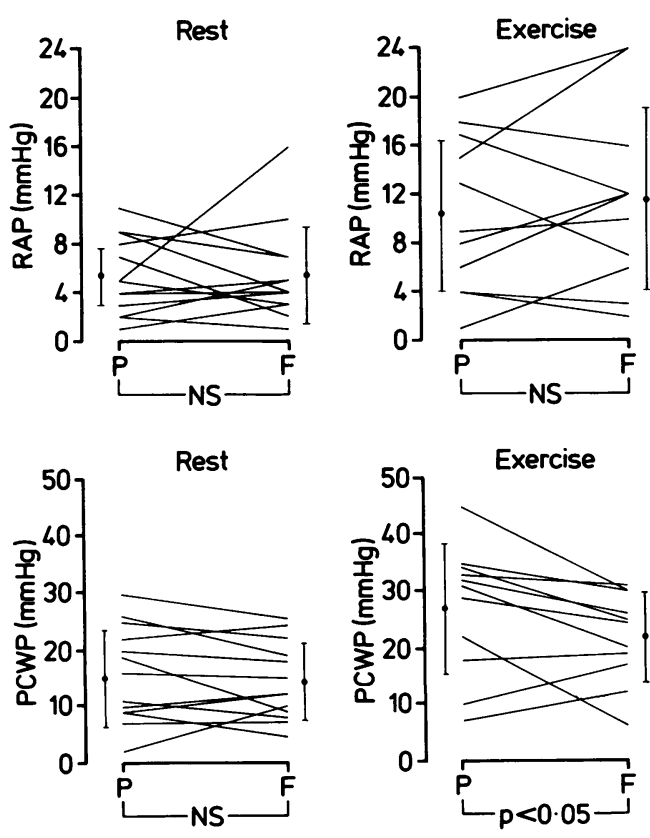

Fig 2 Effects of felodipine on right atrial pressure ( $R A P$ ) and pulmonary capillary wedge pressure (PCWP) compared with those of placebo in each patient at rest and during standard exercise. 

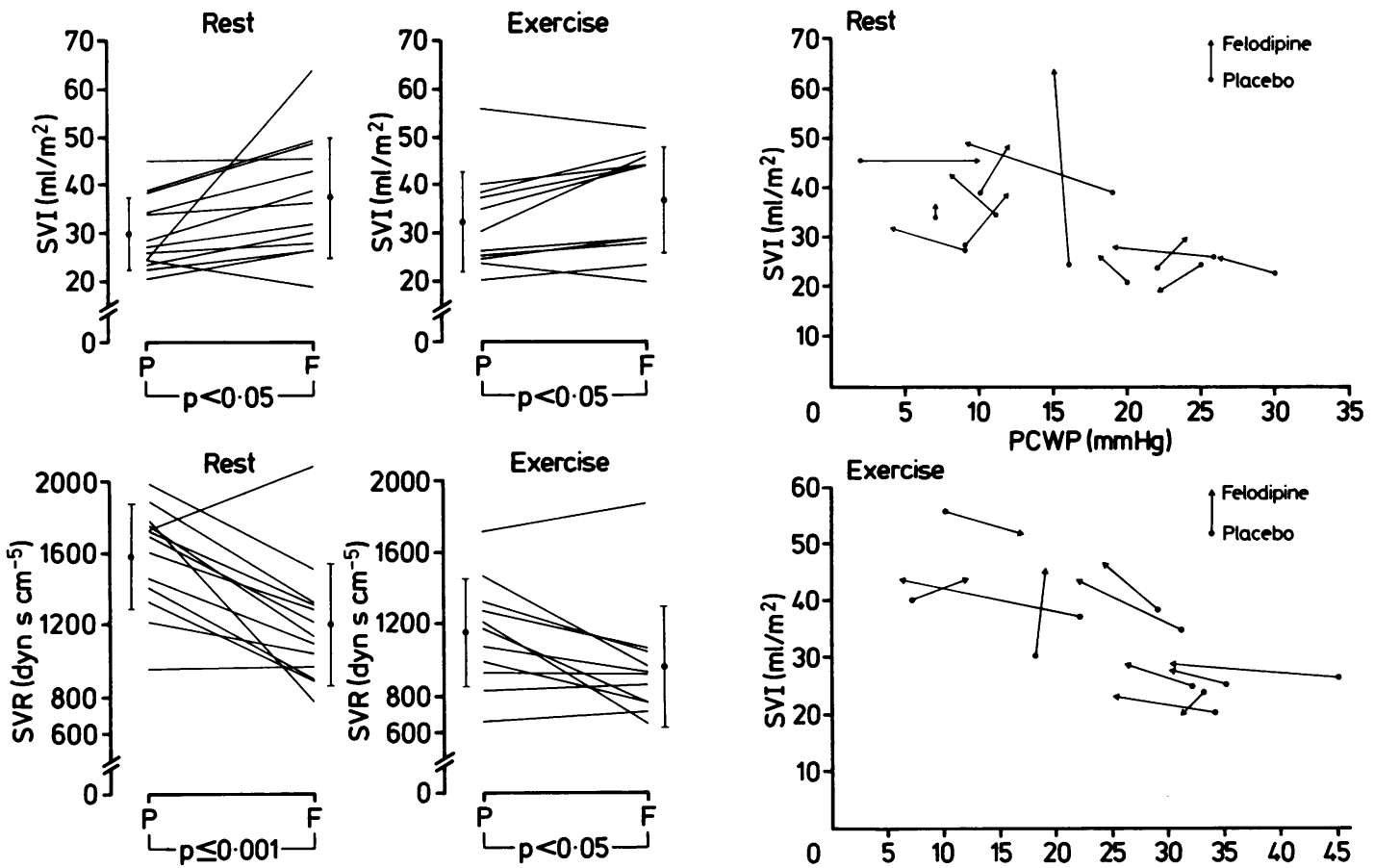

Fig 3 Effects of felodipine on stroke volume index (SVI) and systemic vascular resistance ( $S V R$ ) compared with those of placebo in each patient at rest and during standard exercise.

responses in the initial stages of the treatment periods and we used clinical assessment and the responses of heart rate and blood pressure to determine the dose of vasodilator.

The blood pressure fell during felodipine treatment while the heart rate was unchanged. Preservation of the heart rate despite a fall in arterial pressure is usually seen in patients with more severe congestive heart failure during treatment to reduce the afterload. ${ }^{23}$ Felodipine had a selective effect on car-

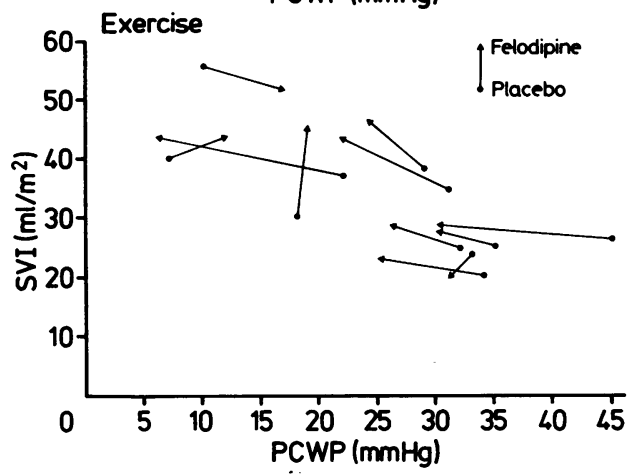

Fig 4 Effects of felodipine on left ventricular function as reflected by the relation between stroke volume index and pulmonary capillary wedge pressure at rest and during standard exercise. Individual changes from placebo to felodipine are shown.

diac loading conditions in the supine resting state. The drug preserved the left ventricular filling pressure and reduced the afterload as shown by the reductions in systemic vascular resistance and arterial blood pressure. The afterload reducing properties of felodipine led to useful increases in stroke volume and subsequently the cardiac output without affecting the heart rate.

Calcium antagonists have predominantly arterial rather than venous effects. ${ }^{19}$ Possible dilatation of

Table Haemodynamic variables during supine rest and upright tilt in ten patients on felodipine or placebo

\begin{tabular}{|c|c|c|c|c|c|c|}
\hline & \multicolumn{3}{|l|}{ Placebo } & \multicolumn{3}{|l|}{ Felodipine } \\
\hline & Supine & Tilt & $p$ & Supine & Tilt & $p$ \\
\hline $\begin{array}{l}\operatorname{RAP}(\mathrm{mm} \mathrm{Hg}) \\
\text { PCWP }(\mathrm{mm} \mathrm{Hg}) \\
\text { HR (beats } / \mathrm{min}) \\
\text { SVR }(\text { dyn s cm } \\
\text { MAP }(\mathrm{mm} \mathrm{Hg}) \\
\text { APP }(\mathrm{mm} \mathrm{Hg}) \\
\text { SVI }\left(\mathrm{ml} / \mathrm{m}^{2}\right) \\
\text { CI }\left(1 / \mathrm{min} / \mathrm{m}^{2}\right)\end{array}$ & $\begin{array}{c}6(1) \\
19(2) \\
85(3) \\
1597(150) \\
97(4) \\
42(3) \\
28(2) \\
2 \cdot 4(0 \cdot 1)\end{array}$ & $\begin{array}{c}0(1) \\
11(2) \\
84(3) \\
1263(100) \\
84(3) \\
42(3) \\
33(2) \\
2 \cdot 8(0 \cdot 2)\end{array}$ & $\begin{array}{l}0.01 \\
0.01 \\
\text { NS } \\
0.01 \\
0.01 \\
\text { NS } \\
0.01 \\
0.01\end{array}$ & $\begin{array}{c}6(2) \\
17(2) \\
80(2) \\
1132(80) \\
84(3) \\
43(3) \\
36(2) \\
2 \cdot 9(0 \cdot 2)\end{array}$ & $\begin{array}{c}1(1) \\
10(2) \\
85(2) \\
1278(50) \\
86(3) \\
38(3) \\
33(2) \\
2 \cdot 8(0 \cdot 2)\end{array}$ & $\begin{array}{l}0.01 \\
0.01 \\
0.01 \\
0.02 \\
\text { NS } \\
0.02 \\
0.02 \\
\text { NS }\end{array}$ \\
\hline
\end{tabular}

RAP, right atrial pressure; PCWP, pulmonary capillary wedge pressure; HR, heart rate; SVR, systemic vascular resistance; MAP, mean arterial pressure; APP, arterial pulse pressure; SVI, stroke volume index; CI, cardiac index. 
venous capacitance vessels by felodipine thus seems an unlikely explanation for the increase in ankle circumference and the lack of an effect on right atrial pressure seen in our patients. Oedema formation during calcium antagonist treatment has been related to pre-capillary vasodilatation and increased capillary pressure and filtration. ${ }^{24}$

Although exercise capacity was not measured, each patient completed a standard workload and duration of supine exercise. During felodipine treatment this standard exercise was achieved at about the same total forward flow (cardiac output) but at substantially lower values of heart rate, arterial pressure, and systemic vascular resistance, at a less exaggerated rise in left ventricular filling pressure, and with improved stroke volume. The importance of the Starling mechanism to left ventricular performance (fig 4) was apparent during the acute volume load of exercise but not at rest in the patients with chronic cardiac overload. ${ }^{25}$ The lower left ventricular filling pressure and the higher stroke volume during standard exercise on felodipine indicate improvement of left ventricular systolic function.

The cardiovascular response to upright tilt is modulated mainly by cardiopulmonary and arterial baroreflexes and is normally directed towards maintaining arterial blood pressure. ${ }^{26}$ The results for cardiac filling pressures show that stimulation of the baroreceptors by orthostatic stress was substantially and equally reduced during both the felodipine and placebo treatment periods (table). During upright tilting on placebo the heart rate failed to increase, systemic vascular resistance fell abnormally, and the arterial pulse pressure but not the mean pressure was maintained. Arterial hypotension and unaltered heart rate together with peripheral vasodilatation during the placebo upright tilt is another example of severely impaired baroreflex cardiovascular control and has been reported in similar subsets of patients with congestive heart failure. ${ }^{27} 28$ Peripheral vasodilatation in response to upright tilting in such patients is an abnormal $\beta$ adrenergic reflex response and may reflect a reduced supraspinal afferent restraint from the baroreceptors in these patients. ${ }^{2728}$

Felodipine treatment did not cause an orthostatic fall in the blood pressure, and the heart rate increased in the upright position. During upright tilting on felodipine the decreased cardiac filling pressures were accompanied by reductions in the stroke volume and arterial pulse pressure whereas the mean arterial pressure was maintained by increased systemic vascular resistance and heart rate (table). Such effects of the drug suggest a normalisation of the baroreflex mediated haemo- dynamic response in our patients, ${ }^{26}$ rather than a non-specific response to a vasodilator. During converting-enzyme inhibition with captopril in patients with congestive heart failure upright tilting did not cause reflex increases in systemic vascular resistance and heart rate and orthostatic hypotension developed. ${ }^{29}$ Another calcium antagonist, nifedipine also has specific baroreflex-mediated effects. ${ }^{30}$

During supine leg exercise in normal subjects the systemic vascular resistance decreases by more than $50 \%$ of its baseline values. ${ }^{31}$ This has been attributed to a pronounced metabolic vasodilatation in the exercising muscles and slight vasoconstriction in the non-exercising parts of the peripheral circulation. ${ }^{32}$ The activation of somatic afferents in exercising muscles is known to increase reflexly the efferent vasoconstrictor impulses to non-exercising vascular beds. ${ }^{32}$ This reflex vasoconstriction has been shown to become markedly augmented in normal individuals during combined exercise and orthostatic stress. ${ }^{33}$ Such an augmented vasoconstriction is attributable to an orthostatic stress-induced reduction of the afferent restraint generated by the baroreceptors. ${ }^{32} \mathrm{~A}$ reduction in baroreceptor afferent restraint during congestive heart failure ${ }^{27}$ could explain excessive vasoconstriction in non-exercising regional circulation. ${ }^{32-34}$

Digitalis can sensitise the baroreceptors in heart failure $^{32}$ and animal experiments have indicated that nifedipine can sensitise the baroreceptors. ${ }^{3032}$ The beneficial haemodynamic response to felodipine that we found in the present study may be related to a baroreceptor-mediated reflex vasodilatation rather than a direct vasodilating effect in the patients with congestive heart failure.

A longer follow up study of the drug is needed to assess its long term clinical efficacy, which should improve both symptoms and haemodynamic estimates of congestive heart failure.

We thank the staff of the Gentofte Hospital Cardiovascular Laboratory and Cardiac Department for excellent technical assistance and Astra-AB, Mölndal, Sweden, for the supply of felodipine.

\section{References}

1 Cohn JN, Franciosa JA. Vasodilator therapy of cardiac failure. N Engl J Med 1977;297:27-31, 254-8.

2 Franciosa JA, Cohn JN. Hemodynamic responsiveness to short- and long-acting vasodilators in left ventricular failure. Am J Med 1978;65:126-33.

3 Packer M, Meller J, Medina N, Gorlin R, Herman MV. Dose requirements of hydralazine in patients with severe chronic congestive heart failure. Am J Cardiol 1980;45:655-60. 
4 Rubin SA, Chatterjee K, Parmley WW. Metabolic assessment of exercise in chronic heart failure patients treated with short-term vasodilators. Circulation 1980;61:543-8.

5 Massie B, Ports T, Chatterjee K, et al. Long-term vasodilator therapy for heart failure: clinical response and its relationship to hemodynamic measurements. Circulation 1981;63:269-78.

6 Franciosa JA, Dunkman WB, Leddy CL. Hemodynamic effects of vasodilators and long-term response in heart failure. $\mathrm{J} \mathrm{Am}$ Coll Cardiol 1984;3:1521-30.

7 Franciosa JA, Cohn JN. Sustained hemodynamic effects without tolerance during long-term isosorbide dinitrate treatment of chronic left ventricular failure. Am J Cardiol 1980;45:648-54.

8 Ader $\mathrm{R}$, Chatterjee $\mathrm{K}$, Ports $\mathrm{T}$, Brundage $\mathrm{B}$, Hiramatsu B, Parmley WW. Immediate and sustained hemodynamic and clinical improvement in chronic heart failure by an oral angiotensinconverting-enzyme inhibitor. Circulation 1980;61: 931-7.

9 Massie B, Kramer BL, Haughom F. Acute and long-term effects of vasodilator therapy on resting and exercise hemodynamics and exercise tolerance. Circulation 1981;64:1218-26.

10 Feldman $R$, Ball $R$, Winchester $M$, Jaillon $P$, Kates RE, Harrison DC. Beneficial hemodynamic response to chronic prazosin therapy in congestive heart failure. Am Heart J 1981;101:534-40.

11 Franciosa J. Effectiveness of long-term vasodilator administration in the treatment of chronic left ventricular failure. Prog Cardiovasc Dis 1982;24:319-30.

12 Walsh WF, Greenberg BH. Results of long-term vasodilator therapy in patients with refractory heart failure. Circulation 1981;64:499-505.

13 Elkayam V, LeJemtel TH, Mathur M, et al. Marked early attenuation of hemodynamic effects of oral prazosyn therapy in chronic congestive heart failure. Am J Cardiol 1979;44:540-5.

14 Colucci WS, Williams GH, Alexander RW, Braunwald E. Mechanism and implication of vasodilatory tolerance in the treatment of congestive heart failure. Am J Med 1981;71:89-99.

15 Packer M, Meller J, Medina N, Yushak M, Gorlin R. Hemodynamic characterization of tolerance to longterm hydralazine therapy in severe chronic heart failure. N Engl J Med 1982;306:57-62.

16 Kramer BL, Massie B, Topic N. Controlled trial of captopril in chronic heart failure. A rest and exercise hemodynamic study. Circulation 1983;67:807-16.

17 Captopril Multicenter Research Group. A placebocontrolled trial of captopril in refractory chronic congestive heart failure. $\mathrm{J} \mathrm{Am}$ Coll Cardiol 1983;2:755-63.

18 Sharpe DN, Murphy J, Coxon R, Hannan SF. Enalapril in patients with chronic heart failure: a placebo-controlled, randomized, double-blind study. Circulation 1984;70:271-8.
19 Braunwald E. Mechanism of action of calciumchannel-blocking agents. $N$ Engl J Med 1982;307:1618-27.

20 Ljung B. Vascular selectivity of felodipine. Drugs 1985;29(suppl 2):46-58.

21 Timmis AD, Campbell S, Monaghan MJ, Walker L, Jewitt DE. Acute haemodynamic and metabolic effects of felodipine in congestive heart failure. Br Heart J 1984;51:445-51.

22 Emanuelsson H, Hjalmarson AA, Holmberg $\mathrm{S}$, Waagstein F. Acute hemodynamic effects of felodipine in congestive heart failure. Eur J Clin Pharmacol 1985;28:489-93.

23 Packer M, LeJemtel TH. Physiologic and pharmacologic determinants of vasodilator response. A conceptual framework for rational drug therapy for chronic heart failure. Prog Cardiovasc Dis 1982;24:275-92.

24 Gustafsson D. Microvascular mechanisms in the formation of oedema caused by calcium antagonists. $J$ Cardiovasc Pharmacol 1987 (in press).

25 Zelis R, Flaim SF, Liedtke AJ, Nellis SH. Cardiovasculatory dynamics in the normal and failing heart. Annu Rev Physiol 1981;43:455-76.

26 Abbound FM, Heistad DD, Mark AL, Schmid PG. Reflex control of the peripheral circulation. Prog Cardiovasc Dis 1976;18:371-403.

27 Kassis E, Amtorp O, Skagen K. Sympathetic reflex control of subcutaneous blood flow in patients with congestive heart failure. Clin Sci 1986;70:513-22.

28 Kassis E, Jacobsen TN, Mogensen F, Amtorp O. Sympathetic reflex control of skeletal muscle blood flow in patients with congestive heart failure. Evidence for a beta-adrenergic circulatory control. Circulation 1986;74:929-38.

29 Cody RJ, Franklin KW, Kluger J, Laragh JH. Mechanisms governing the postural response and baroreceptor abnormalities in chronic congestive heart failure: effects of acute and long-term converting-enzyme inhibition. Circulation 1982;66: 135-42.

30 Heesch CM, Abboud FM. Effects of nifedipine on cardiac baroreflex control of renal nerve activity [Abstract]. Circulation 1982;66 (suppl 2):34.

31 Thadani U, Parker JO. Hemodynamics at rest and during supine and sitting bicycle exercise in normal subjects. Am J Cardiol 1978;41:52-9.

32 Abboud FM, Thames MD. Interaction of cardiovascular reflexes in circulatory control. In: Shepherd JT, Abboud FM, eds. Handbook of physiology-the cardiovascular system. Bethesda, Maryland: American Physiological Society, 1983:675-753.

33 Walker JL, Abboud FM, Mark AL, Thames MD. Interaction of cardiopulmonary receptors with somatic receptors in man. $J$ Clin Invest 1980;65:1491-7.

34 Zelis R, Flaim SF. Alterations in vasomotor tone in congestive heart failure. Prog Cardiovasc Dis 1982;25:437-59. 